\title{
0 telespectador como detetive: aproximações à experiência televisiva contemporânea a partir de True Detective ${ }^{1}$
}

Bruno Souza Leal e Felipe Borges

\section{Resumo}

A partir do estudo da primeira temporada de True Detective, 0 artigo explora a imagem do telespectador contemporâneo como um detetive em busca de sentidos e relações para as narrativas com as quais se envolve. 0 programa da HBO, cuja trama é guiada por narradores não confiáveis, convoca um telespectador interessado em "perfurar" e "reassistir" sua narrativa, conforme terminologia cunhada por Jason Mittell (2009). Ao longo do trabalho, refletimos em que medida essa postura telespectatorial, que encontra paralelo com o leitor desconfiado destacado por Paul Ricoeur (2010), constitui um movimento crítico para além da série ou se esgota num prazer metanarrativo. No caso de True Detective, a própria possibilidade de um discurso conter uma verdade é colocada em xeque, no que pode ser sua principal contribuição no que tange à atuação do telespectador-detetive.

\section{Palavras-Chave}

Narrativa. Série. Telespectador. Televisão. Ficção.

Bruno Souza Leal | brunosleal@gmail.com Doutor em Estudos Literários pela Universidade Federal de Minas Gerais - UFMG, Brasil. Professor permanente do Programa de PósGraduação em Comunicação da UFMG. Coordenador do Núcleo de Estudos Tramas Comunicacionais: Narrativa e Experiência - UFMG. Pesquisador do CNPq e da Fapemig.

Felipe Borges | felipelsborges@gmail.com

Mestre com bolsa CAPES pelo Programa de Pós-Graduação em Comunicação da Universidade Federal de Minas Gerais - UFMG, Brasil. Integrante do Núcleo de Estudos Tramas Comunicacionais: Narrativa e Experiência - UFMG.

\section{Introdução}

As séries ficcionais estão entre aqueles produtos que melhor materializam as mudanças sofridas pela televisão nas últimas décadas, quando passam a ser consumidas fora do fluxo da programação tradicional e do próprio televisor. Com a pirataria por downloads, o surgimento de plataformas de streaming e on demand (como Netflix, Amazon Prime, Hulu, HBO GO e Globo Play) e o advento de recursos como o "Pausar" e 0 "Voltar" nos próprios canais por assinatura, as relações entre televisão e telespectador passaram (e continuam a passar) por importantes mudanças. Um dos estudiosos que mais reconhecidamente buscou caracterizar esse conjunto de transformações foi Jason Mittell (2009, 2011, 2012), que, através da expressão "narrativa complexa", tentou abarcar não só novos modos de contar histórias na produção televisual, como também inéditas posturas e atitudes dos telespectadores. Ele define que a narrativa complexa emerge nos anos 1990 e,

[...] em seu nível mais básico, é uma redefinição de formas episódicas sob a influência da narração em série - não é necessariamente uma 
fusão completa dos formatos episódicos e seriados, mas um equilíbrio volátil. Recusando a necessidade de fechamento da trama em cada episódio, que caracteriza o formato episódico convencional, a complexidade narrativa privilegia estórias com continuidade e passando por diversos gêneros (MITTEL, 2012, p. 36).

Mittell destaca séries como The X-Files (FOX, 1993-2002; 2016), que envolve tanto 0 "monstroda-semana" (forma episódica) como uma mitologia de arco contínuo, no qual a trama e as relações dos personagens se desenrolam progressivamente (forma seriada). Ele argumenta que, na narrativa complexa, "[...] assistimos ao processo de narração como uma máquina mais do que nos engajamos em sua diegese" (MITTEL, 2012, p. 43). Dessa maneira, há um convite claro para que os telespectadores pensem não somente a trama da série, mas a própria maneira como ela é desenvolvida - um estímulo para a reflexão a respeito do funcionamento das engrenagens narrativas. Como defendem Glòria Corretger e Fran Burian,

A maioria desses relatos se mostra consciente de sua natureza labiríntica. Por esse motivo, em determinado momento da série, coloca-se em evidência ante os olhos do espectador a complexidade da estrutura serial. Aparece aquilo que denominamos "0 mapa da série" (CORRETGER; BURIAN, 2011, p. 48, tradução nossa). ${ }^{2}$
Uma das séries que, nos últimos anos, reconhecidamente incorporou esse jogo narrativo com os telespectadores foi True Detective (HBO, 2014-), particularmente em sua primeira temporada. Não por acaso, a série apresenta uma narrativa que dialoga intensamente com diferentes dimensões da ampla e diversa tradição - literária, cinematográfica, televisiva - das chamadas "histórias de detetive". Não parece ser gratuita, portanto, a semelhança sugerida por Mittell entre 0 telespectador contemporâneo e 0 leitor/espectador das narrativas criminais. ${ }^{3}$ Afinal, ambos colocam para si um desafio investigativo, de saber mais, elaborado a partir das pistas apresentadas no universo diegético, em um agir simultaneamente em sintonia e à revelia do que é proposto nas histórias. Nesse sentido, a partir de uma leitura do jogo narrativo da primeira temporada de True Detective, este artigo explora a imagem do telespectador contemporâneo como um detetive, num movimento reflexivo que envolve a revisão e o cotejamento entre alguns postulados de Mittell e os estudos sobre as narrativas criminais e seus interlocutores. Uma vez que a narrativa criminal está presente em romances, filmes e séries e é tema de estudo de diferentes correntes teóricas, optamos aqui por transitar por

Uma versão inicial deste artigo foi apresentada no XXVI Encontro Anual da Compós, em São Paulo (SP), ocorrido entre 06 e 09 de junho de 2017. Agradecemos fortemente a recepção crítica que o artigo recebeu e a colaboração dos colegas ali presentes.

2 La mayoría de estos relatos se muestran conscientes de su naturaleza laberíntica. Por ese motivo, en algún momento de la serie se pone en evidencia ante los ojos del espectador la complejidad de la estructura serial. Aparece lo que nosotros denominamos "el mapa de la serie".

3 A terminologia que envolve as narrativas criminais é ampla e frequentemente se sobrepõe. Para este artigo, optamos pela expressão "narrativa criminal" como forma de abarcar a diversidade de obras dessa larga tradição. 
ao menos parte desse rico acervo, preservando os termos ali utilizados (como leitor, espectador, autor etc.), ao mesmo tempo respeitando as diferenças de perspectivas e obras de referência e observando as similaridades entre elas.

\section{True Detective e o jogo não confiável de contar histórias}

Na primeira temporada de True Detective, acompanhamos os trabalhos de Martin "Marty" Hart e Rustin "Rust" Cohle, detetives da Divisão de Investigação de Crimes da Louisiana. A primeira cena da série introduz, de maneira obscura, 0 assassinato com traços ocultistas de Dora Lange. É sobre esse caso que a dupla de policiais irá se debruçar ao longo dos oito episódios, em diferentes épocas: em 1995, durante a investigação inicial; em 2002, quando novos elementos do caso são descobertos; e em 2012, momento em que os policiais retomam os trabalhos sobre o mistério de Dora. Na fase mais recente da narrativa, em 2012, vemos Marty e Rust prestando depoimentos, separadamente, a outros dois detetives, Thomas Papania e Maynard Gilbough, relatando como foram as investigações de 1995 e 2002. Assim como os protagonistas, desconhecemos a razão para tal interrogatório, mas acompanhamos os desdobramentos do caso de Dora a partir de idas e vindas entre as três fases.
Ainda que narre a princípio uma investigação em busca de quem matou Dora, True Detective se apresenta como uma série sobre contar histórias, sobre narrar a fim de tentar propor sentidos, gerar entendimentos e estabelecer sequências temporais acerca do que parece incoerente, fugidio, vago. A série explora a fragmentação da realidade na própria maneira como sua intriga é tecida, por meio de diferentes pontos de vista, o que faz com que a história deixe de ser apenas uma para se tornar várias. Para Ana Maria Bahiana,

[...] este primeiro True Detective era sobretudo sobre contar histórias. A história de 1995. A história de 2002. A história de 2012. A história de Cohle, a história de Hart, a história que eles contam um ao outro, que eles contam aos detetives em 2012, que eles contam a si mesmos. A história que nós estamos vendo. E no fim, uma história muito antiga - a coragem necessária para entrar num labirinto sabendo, com certeza, que "no final há um monstro" (BAHIANA, 2014, s/p).

Essa perspectiva é compartilhada pelo showrunner e roteirista da série, Nic Pizzolatto, quando ele afirma, em entrevista: "True Detective assinala a todo momento que tudo é uma história; o que você conta a si mesmo sobre quem você é, o que você conta a si mesmo sobre o que é 0 mundo" (JENSEN; PIZZOLATTO, 2014, p. 24, tradução nossa). ${ }^{4}$ Para Pizzolatto, a série aborda um dos temas que mais nos fascinam sobre nós mesmos e sobre nossa cultura: o que fazemos com as histórias (JENSEN; PIZZOLATTO, 2014). 
A maneira como a intriga da série é tecida, por meio do relato dos protagonistas, levanta, porém, algumas questões problemáticas: até que ponto seus relatos são confiáveis?

A narrativa de True Detective se desenvolve por meio do depoimento de Marty e Rust sobre o caso de Dora; é a partir de suas falas, principalmente, que 0 antigo evento é retomado. Por mais que as versões de Marty e Rust sigam, até certo ponto, em concordância uma com a outra, são perspectivas diferentes, que rompem a unicidade narrativa. True Detective se desenvolve, portanto, a partir do esquema de narrativa encaixada, em que, como classicamente definiu Tzvetan Todorov,

a aparição de uma nova personagem ocasiona infalivelmente a interrupção da história precedente, para que uma nova história, a que explica 0 "eu estou aqui agora" da nova personagem, nos seja contada. Uma história segunda é englobada na primeira; esse processo se chama encaixe (TODOROV, 2006, p. 122).

Nessa construção narrativa, como lembra Todorov, "cada nova personagem ocasiona uma nova história" (2006, p. 123). Em True Detective, os relatos se acumulam e se contradizem, até que percebemos que não podemos confiar em ninguém - muito menos nos policiais, que supostamente seriam as autoridades responsáveis por fazer justiça e encontrar a verdade. Além disso, é importante destacar: mesmo o macronarrador da série joga com pistas enganosas. Ao final do quinto episódio, The secret fate of all life, por exemplo, os detetives Papania e Gilbough, em 2012, finalmente revelam acreditar que Rust é culpado pelos crimes. A montagem da sequência - em que se intercalam as falas de ambos enumerando as bases de sua acusação com imagens de Rust em atitude suspeita, e na qual Marty parece inseguro sobre seu antigo parceiro, sob uma trilha sonora de suspense - entrega: Rust pode ser mesmo 0 assassino. Como descobrimos, trata-se de mais um ardil narrativo. Em outros casos (a identidade dos cinco homens mascarados envolvidos em rituais assassinos, o possível abuso sexual sofrido por uma das filhas de Marty, a natureza do misterioso Rei Amarelo etc), as pistas lançadas por True Detective para o telespectador não se revelam verdadeiras ou falsas, mas permanecem dúbias, suscitando diversas leituras possíveis e potencializando a porosidade da série.

Em True Detective, o embaralhamento temporal é parte essencial e fundante da trama e seu jogo de pistas incertas. Por exemplo: ao final do terceiro episódio, The locked room, subitamente encontramos Marty irritado com seus interrogadores, em 2012. Não vemos o que lhe foi perguntado, apenas ouvimos sua resposta: "Se vocês querem me perguntar, me perguntem. Já estiveram num tiroteio?". Simplesmente não temos ideia do que ele está falando; as cenas não sugerem nenhum tiroteio à vista. Após essa sequência, vemos um lugar no meio do mato e ao final a cena congela num homem que anda por lá, usando uma máscara de gás. Não sabemos que local é esse, mas podemos suspeitar, diante do relato em off de Rust sobre 0 "monstro no 
fim do sonho", que a misteriosa figura é Reggie

Ledoux - personagem que surgira logo antes como principal suspeito do crime de Dora. Só iremos ter certeza que é mesmo ele, porém, dali a dois episódios, quando acompanhamos, em 1995, os detetives finalmente descobrindo onde estava 0 suspeito e adentrando o matagal. Este era seu esconderijo e laboratório de drogas, e inferimos que a postura defensiva de Marty na conversa com seus interrogadores é uma reação à pergunta sobre 0 suposto tiroteio que aconteceu ali mesmo, do qual Reggie e seu primo DeWall Ledoux saíram mortos. No entanto, não houve nenhuma troca de tiros: Marty, revoltado com os crimes de Reggie, assassinou-o enquanto ele estava algemado, ao passo em que Rust acabou matando DeWall, que tentava fugir. 0 tiroteio foi uma ficção criada pelos dois detetives para se livrar de problemas com a justiça, numa farsa exposta a nós pelo macronarrador, que apresenta as cenas da matança, destoantes da narrativa de Marty e Rust.

Esse e outros exemplos ilustram como a série, em sua fragmentação, demanda um telespectador, como um detetive, atento aos detalhes, capaz de juntar as peças apresentadas pelos seus narradores. Sem essa atenção, pistas importantes e detalhes fundamentais passam despercebidos e prejudicam não só o prazer em acompanhar 0 programa, mas o próprio entendimento de sua trama. Afinal, há pouca redundância em True Detective, como podemos constatar no modo como é apresentada uma evidência central para resolver o caso de Dora: 0 retrato falado do assassino, Errol Childress. 0 documento surge no primeiro episódio da série, numa breve sequência, e só é retomado como pista importante para a investigação no sétimo, After you've gone. Similarmente, a pista da casa pintada de verde, surgida no último episódio (Form and void) e essencial para se chegar ao assassino, remete a uma cena que dura menos de 5 segundos no segundo episódio (Seeing things), quando Rust tira a foto que Marty irá usar na comparação em 2012. É somente porque se pode voltar na cena e reassistir ao episódio que somos capazes de notar esses elementos, quando sabemos o que já aconteceu e identificamos as engrenagens narrativas.

É daí que surgem as teorias dos fãs de True Detective, debatidas em fóruns como o Reddit e em sites e blogs diversos (como io9, Vulture, Wired, Slate, Bustle, The Vigilant Citizen, Across the Margin), que questionam os entendimentos dos fatos narrados, propondo outras significações ou simplesmente apontando as pistas falsas ou sem explicação que afloram ao longo dos episódios, especialmente as que dizem respeito ao Rei Amarelo, para quem são voltados os rituais ocultistas na série e cuja identidade jamais é revelada. A lista de teorias e especulações sobre diversos elementos da trama é vasta e não caberia discuti-las neste trabalho. 0 que nos interessa é atestar como esses itens obscuros (intencionais ou não) surgem como rastros do texto, aberto a diversas leituras capazes de levar a múltiplas interpretações sobre a série. 
A possibilidade de explorar ao máximo o texto se relaciona não só às características das produções da HBO, mas também de programas de outras redes, como The killing (AMC/NETFLIX, 20112014), Top of the lake (BBC/SundanceTV, 2013-) e River (BBC, 2015), entre outras. Trata-se de produções em que cada episódio dura acima de 45 minutos, ao final dos quais não é preciso resolver o mistério, já que ele se prolonga por toda a temporada (às vezes até mais). No tempo dessas séries de TV, há uma espécie de sedução do telespectador, que precisa se atentar a cada detalhe que é apresentado, a cada pista em potencial, por mais disfarçada que ela esteja. Perder os pormenores significa não só ser ludibriado pela narrativa, como também desperdiçar a chance de propor sentidos instigantes para a trama.

No caso específico da narrativa criminal, essa discussão ganha novos contornos a partir da recorrente analogia entre detetive e leitor, feita por autores como Antoine Compagnon (1999), Vera Figueiredo (2013), Julio Jeha (2011), Carl D. Malmgren (2001) e Glenn W. Most (1983). Para Most (1983), o detetive é a figura que representa o leitor no texto, pois as atividades de ambos são correlatas: tanto no objetivo (buscam solucionar o mistério do crime), quanto na duração (detetive e leitor estão engajados na história desde 0 começo e saem de cena assim que o enigma é resolvido, quando a trama se encerra) e no método (uma mistura de adivinhação e memória, suspeita e lógica). Numa linha de pensamento semelhante, Jeha escreve:

\begin{abstract}
0 detetive substitui o leitor no texto, uma vez que 0 detetive deve ler, nas pistas que encontra, um texto escrito por um criminoso. Entretanto, 0 assassino tenta esconder a sua história criando uma ficção - um álibi - que oculte a verdadeira história do crime. Assim, 0 assassino torna-se 0 autor de um relato em forma de palimpsesto que reclama para si 0 estatuto de verdade. 0 detetive se vê forçado a interpretar o texto - 0 álibi - de modo a ser capaz de descobrir a história oculta que é a verdadeira versão dos fatos. A ficção de detetive tradicional termina com o detetive produzindo outra narrativa, que explica e interpreta a ficção do criminoso (JEHA, 2011, p. 1).
\end{abstract}

Testemunhamos, como leitores ou telespectadores, portanto, um jogo de verdades e mentiras estabelecido em torno do crime, que se apresenta como um texto criado pelo criminoso para enganar o detetive. Esperase que este, não obstante, seja um leitor astuto, capaz de ler nas entrelinhas a suposta verdade mascarada. Segundo essa lógica, True Detective atualiza, no sentido pleno da palavra, uma característica chave das narrativas criminais (a identificação detetiveleitor/espectador) para construir uma história em que engano, verdade, mentira, investigação e modos de saber se interpenetram e entram em questão, a partir de um jogo em que narradores pouco confiáveis desafiam seus interlocutores (entre eles, cada um de nós, telespectadores).

\section{Um telespectador de segundo nível?}

A experiência televisual de True Detective está baseada no fenômeno batizado por Mittell de 
"reassistibilidade"5 (2011), que é, simplesmente, a possibilidade de rever um programa televisivo, algo impensável em tempos idos (a não ser em reprises, igualmente fugazes). Para 0 autor, a reassistibilidade nos possibilita o "rever analítico", cujo objetivo é "[...] principalmente uma análise aprofundada, tentando dar sentido às estruturas do texto, à mecânica, à poética ou mesmo ao plot" (MITTEL, 2011, s/p., tradução nossa). ${ }^{6}$ Nota-se, assim, que se trata de um recurso importante para o sabor da narrativa complexa, como destaca Christian Pelegrini:

Mittell indica que a reassistibilidade se sustenta em diversas práticas de leitura. Por um lado, permite que a fruição em cada "leitura" do texto televisual seja diferente. É possível buscar elementos nos textos que não haviam sido percebidos anteriormente; relações isotópicas, elementos intertextuais e sentidos não percebidos até então. Em cada "assistida", obtemos algo novo (PELEGRINI, 2012, p. 643).

Assim, quando revemos um episódio, uma temporada ou toda a série, temos uma nova experiência, tendo em vista que podemos reparar em detalhes outrora despercebidos. Mittell propõe uma analogia da experiência da reassistibilidade com a das narrativas criminais, ao dizer: "[a]ssim, quando reassistimos a um filme quebra-cabeça ou relemos um romance de mistério, nós o fazemos com pleno conhecimento do final e analisamos a virada narrativa em conformidade" (MITTEL, 2011, s/p., tradução nossa). ${ }^{7}$ Ao saber 0 que irá acontecer numa trama de mistério, podemos nos deter sobre o como, sobre a maneira pela qual as pistas são colocadas e as estratégias desenhadas pelo jogo narrativo para envolver (e ludibriar) 0 telespectador.

Interessante notar como a reassistibilidade, por mais que diga de um ver de novo, envolve um prazer diferente daquele destacado por Umberto Eco (1989) sobre a nossa experiência com as séries de televisão. Tendo como referência as características narrativas e de exibição da TV aberta, em que nos reencontramos com os mesmos personagens, cenários e tramas semana após semana, 0 autor afirma:

Na série, o leitor acredita que desfruta da novidade da história enquanto, de fato, distrai-se seguindo um esquema narrativo constante e fica satisfeito ao encontrar um personagem conhecido, com seus tiques, suas frases feitas, suas técnicas para solucionar problemas... A série neste sentido responde à necessidade infantil, mas nem por isso doentia, de ouvir sempre a mesma história, de consolar-se com o retorno do idêntico, superficialmente mascarado (ECO, 1989, p. 123).

Como pontua Pelegrini (2012), na versão em português do artigo Narrative Complexity in Contemporary American Television, publicada na revista Matrizes, opta-se por traduzir "rewatchability" por "reassistência", cujo significado é o mesmo.

[...] primarily close analysis, trying to make sense of the text's structures, mechanics, poetics, or even plot.

Thus when we rewatch a puzzle film or reread a mystery novel, we do so with full knowledge of the ending and analyze the twisty plot accordingly. 
0 "retorno ao mesmo" em Mittell, por sua vez, envolve a emersão de um texto diferente daquele mesmo programa - é o prazer da descoberta, e não o do reencontro com 0 familiar. 0 telespectador retorna à série não apenas pelo apreço por determinado universo narrativo (que certamente é fator determinante), nem pelo apelo à formula narrativa adotada, mas porque ainda não se deu por satisfeito em relação aos sentidos por ele propostos numa primeira investida.

No cenário em que proliferam narrativas complexas e no qual contamos com o recurso da reassistibilidade, outros dois conceitos de Mittell, correlatos a esses, são pertinentes: 0 da "perfurabilidade" do texto (MITTELL, 2009) e 0 do "fandom forense" (MITTELL, 2009). A perfurabilidade diz respeito às séries que encorajam os telespectadores a cavar mais fundo "[...] sondando sob a superfície para entender a complexidade de uma história e de seu contar. Esses programas criam ímãs para engajamento, atraindo telespectadores para mundos narrativos e exortando-os a se aprofundar para descobrir mais" (MITTELL, 2009, s/p, tradução nossa) ${ }^{9}$ Mittell salienta que tais séries convidam, nesse sentido, a toda uma exploração de sua mitologia em fóruns na internet. A perfurabilidade incita a exploração de um universo narrativo e, em parte, diz respeito à própria capacidade de um programa de convocar outros textos e referências em seu processo de ressignificação. A reassistibilidade e a perfurabilidade permitem, assim, a plena constituição de um leitor mais crítico, já que lhe é propiciada a chance de pensar as estratégias e diálogos textuais.

Já o "fandom forense" não por acaso é mais uma analogia com o universo das narrativas criminais, tendo em vista que se trata de uma verdadeira dissecação da trama das séries, com o objetivo de esmiuçar diversos elementos diegéticos e propor novos sentidos. Os telespectadores "[...] se comportam como peritos forenses, no sentido de fazerem uma coleta minuciosa de dados, catalogálos, observar a obra fotograma por fotograma" (TOLED0, 2016, p. 5). Conforme Mittell:

Essa estética operacional está demonstrada na dissecação feita por fãs em fóruns na internet das técnicas utilizadas nas comédias e dramas complexos para guiar, manipular, iludir e desviar a atenção dos espectadores dando a entender que a principal fruição é desvendar como operam os procedimentos narrativos (MITTEL, 2012, p. 42).

Nesse processo, o resultado é que a suposta resposta final oferecida por uma série cai: "Se para 0 espectador/investigador há uma 'verdade

Adotamos a tradução "perfurabilidade" para o termo "drillable" a partir de Glauco Toledo (2016). Toledo propõe a expressão "fanatismo forense" como equivalente para o original "forensic fandom". Entretanto, optamos por "fandom forense" tendo em vista que a expressão "fandom" já é largamente utilizada no Brasil.

[...] probing beneath the surface to understand the complexity of a story and its telling. Such programs create magnets for engagement, drawing viewers into story worlds and urging them to drill down to discover more. 
diegética oficial', chamada de cânone ficcional, torna-se importante para 0 grupo de fanáticos que haja supervisão dessa característica" (TOLEDO, 2016, p. 7). Segundo Marcel Silva, essa relação entre séries e público é fundamental para entendermos a cultura das séries:

Trata-se de novas e complexas dinâmicas espectatoriais que são gestadas no seio das comunidades de fãs, através de trocas simbólicas e materiais pelos fãs entre si, dos fãs para as emissoras e das emissoras para os fãs. É, de fato, um processo comunicacional muito complexo, que faz emergir o modo dialético e inter-relacionado por meio do qual se dão as relações entre a grande mídia e seu público (SILVA, 2014, p. 248).

É a partir dessa circulação que se forma uma comunidade interpretativa das séries - como acontece em True Detective. Parece apropriado dizer então que, em certa medida, 0 telespectador atendido pela narrativa complexa é uma variação do leitor de segundo nível previsto por Eco, anos antes de Mittell, ao tratar de narrativas seriadas televisivas:

Todo texto pressupõe e constrói sempre um duplo Leitor Modelo. 0 primeiro usa a obra como um dispositivo semântico e é vítima das estratégias do autor que 0 conduz passo a passo ao longo de uma série de previsões e expectativas; 0 outro avalia a obra como produto estético e avalia as estratégias postas em ação pelo texto para construí-lo justamente como Leitor Modelo de primeiro nível. [...]. Poderíamos aliás classificar as produções narrativas seriadas num continuum que leva em consideração as diversas graduações do contrato de leitura entre texto e leitor de segundo nível ou leitor crítico (como sendo o oposto do leitor ingênuo). É evidente que até 0 produto narrativo mais banal permite ao leitor constituir-se, por decisão autônoma, em leitor crítico, isto é, em leitor que decide avaliar as estratégias inovadoras, ainda que mínimas, ou registrar a ausência de inovação. Há, porém, obras seriais que estabelecem um pacto explícito com o leitor crítico e por assim dizer 0 desafiam a destacar as habilidades inovadoras do texto (ECO, 1989, p. 129-130, grifos do original).

Como Mittell, Eco também sugere certa preocupação do telespectador de segundo nível não apenas com a diegese, mas com as estratégias do autor, com a engrenagem narrativa. Para isso, exemplifica com a série Columbo (NBC, 19681978; ABC, 1989-2003):

0 espectador não é convidado tanto ao jogo ingênuo das previsões (whodunit?), quanto, por um lado, a divertir-se com a execução das técnicas de investigação de Colombo [...], e por outro a descobrir como 0 autor conseguirá vencer seu desafio: que consiste em fazer Colombo fazer aquilo que faz sempre, e, todavia, não de modo banalmente repetitivo (ECO, 1989, p. 130).

De forma similar, Mittell defende que, "[...] como em toda ficção baseada em mistério, os espectadores querem ser surpreendidos e desbancados ao mesmo tempo em que satisfeitos com a lógica interna da história" (2012, p. 49). Ainda sobre a experiência do leitor crítico de Eco, salienta-se que ele se satisfaz também ao reconhecer as estratégias extratextuais do autor, que convoca outros textos no filme ou série (ECO, 1989). Logo, há um prazer em reencontrar tramas, cenários, personagens e situações recorrentes no imaginário da narrativa criminal, por exemplo. 
0 policial "durão", a dupla conflituosa de detetives, 0 vilão fascinante e carismático ou doentio, as mulheres fatais: tais elementos voltam seguidamente, atualizados e reconfigurados em textos recentes como True Detective, numa dinâmica de retomadas e renovações.

Importante ressaltar que promovemos uma aproximação entre 0 telespectador da narrativa complexa e o leitor de segundo nível apenas até certo ponto, uma vez que este é considerado por Eco uma espécie de leitor-modelo. 0 leitormodelo é aquele previsto pelo autor, "[...] concebido como a contrapartida ideal de um autor-modelo" (EC0, 2005, p. 77), que irá, por assim dizer, "jogar conforme as regras do jogo", "compreendendo" a mensagem textual. Por outro lado, ainda que fale de uma "estética do jogo", em que o público é convidado a jogar junto com os criadores no desvendamento de códigos interpretativos, Mittell desdobra o telespectador das narrativas complexas em pelo menos dois estatutos distintos: como uma projeção dos produtores, ou seja, como "modelos de leitores", para usar a terminologia de Eco, e como a descrição de comportamentos identificados entre consumidores reais. Com isso, Mittell sugere inclusive a existência de um telespectador mais interessado em subverter a dinâmica narrativa, extrapolando as potenciais significações que lhe foram inicialmente oferecidas. É essa indisciplina que ganha força diante das mudanças pelas quais a televisão passou nos últimos tempos, quando se reconfiguram as práticas de telespectatorialidade.

\section{Não confiar}

A apreensão da narrativa como um jogo entre autor e leitor, para usarmos os termos típicos dos estudos literários, ou os produtores e os telespectadores, numa adaptação ao universo televisivo, estabelece um desafio em torno de saber "o que acontece", "o que significam" pistas e referências, altamente dependente de uma figura fundamental: o narrador. Nos casos em que esse narrador se revela confiável, o jogo se torna mais seguro, menos perigoso por assim dizer, uma vez que leitor ou telespectador pode se basear nas pistas apresentadas para descobrir quem matou, o que aconteceu etc. 0 mesmo não se dá quando o narrador é pouco digno de confiança. Essa construção, relativamente recente no horizonte das narrativas - televisivas, romanescas, cinematográficas etc. - marca uma ruptura com aquelas histórias em que o narrador "leva o leitor pela mão", intervindo sempre que necessário para esclarecer dúvidas, recuperar informações, orientar 0 entendimento acerca de personagens e acontecimentos. Se, para muitos (B00TH, 1980; RICOEUR, 2010), esse narrador confiável teria seu auge no século XVIII mesmo sendo presente até hoje -, já ao longo do século XIX e do século XX diferentes narrativas, muitas vezes marcadas pela ironia, exigiram novas atitudes dos leitores.

Como observa Paul Ricoeur (2010), o narrador não confiável tem como contrapartida a responsabilidade e a liberdade do leitor para 
dizer o que acontece, dar sentido à história.

Para 0 filósofo francês, 0 exercício de crítica às convenções sociais (e também morais, epistêmicas, estéticas) encontra nesse narrador um recurso importante. Por isso mesmo, essas narrativas seriam perigosas, pois, demandando "um leitor que responda", suscitam inquietação e crítica. Por outro lado, Ricoeur, tendo como referência a experiência literária, deixa claro que as narrativas marcadas pela não confiabilidade colocam em xeque 0 lugar de autor, tão fundamental para identificação das obras e de suas histórias. Diz ele (numa crítica clara a Wayne Booth):

É nesse ponto que uma retórica da ficção centrada no autor revela seu limite: ela só conhece uma iniciativa, a de um autor ávido para comunicar sua visão das coisas. No tocante a isso, a afirmação de que um autor cria seus leitores parece carecer de uma contrapartida dialética. Talvez seja função da literatura mais corrosiva contribuir para fazer aparecer um leitor de um novo tipo, um leitor ele mesmo desconfiado, porque a leitura deixa de ser uma viagem tranquila feita em companhia de um narrador digno de confiança e se torna um combate com 0 autor implicado, um combate que 0 reconduz a si mesmo (RICOEUR, 2010, p. 279).

Como se vê, a valorização do narrador não confiável por Ricoeur baseia-se na perda da autoridade do autor, no reconhecimento de uma função crítica para as narrativas e, além disso, de um caráter reflexivo da experiência de leitura, em que o leitor, ao desconfiar da história, desconfia também de si mesmo. Com isso, a não confiabilidade da narrativa está diretamente ligada à proposição de uma experiência de leitura ou espectatorial marcada pela crítica e por uma autonomia de ação por parte do leitor/ espectador. É essa autonomia que torna possível tanto a reassistibilidade quanto a perfurabilidade identificadas por Mittell. Nesse sentido, a imagem do telespectador como um detetive, como um investigador, parece se encaixar perfeitamente. Porém, resta saber se a adesão, o engajamento do telespectador tem a força de crítica às convenções sociais identificada por Ricoeur na literatura corrosiva ou inconformada ou se esgotaria numa espécie de prazer metanarrativo, que, ao fim e ao cabo, não se prolongaria para além da própria série.

\section{Em True Detective, se o macronarrador da} série não confia nos investigadores em sua busca pela verdade (na medida em que eles mentem), o mesmo parece acontecer com 0 telespectador, desconfiado em relação à verdade diegética do programa e que por isso se lança no tecer de uma teia de sentidos sem fim. Sobre a experiência do telespectador com a série da HB0, Iván de los Ríos reflete:

Bailemos, descubramos algum escritor que não conhecíamos, leiamos por fim esse outro, sigamos alguma pista falsa, penduremos arquivos e imagens numa parede para tentar visualizar nosso caso, dêmos um passo para trás, há fotos de autores mortos e vivos, citações desconexas, capas de livros. [...] Queremos saber mais [...]. Saber tudo. Queremos descobrir os referentes literários da narração audiovisual enquanto avança a sequência e os protagonistas descobrem 0 assassino. Du- 
pla investigação, duplo prazer? (2014a, p. 35, tradução nossa). ${ }^{10}$

A busca por referências e significações encontra um ponto central no Rei Amarelo, figura que assombra os personagens de True Detective e sintetiza essas duas possibilidades: tanto a de conhecer outros textos que compõem a série quanto a de propor respostas para o mistério. No primeiro caso, a macabra figura remete ao livro $O$ rei de amarelo (The king in yellow, 1895), de Robert W. Chambers - que é apenas um dos textos com os quais True Detective trava um diálogo explícito. Trata-se do prazer de enxergar e explorar os diversos textos que compõem determinada obra, tal como observam Eco (1989) e Figueiredo (1988) e conforme explicitado por Ríos:

Por suas múltiplas referências literárias e filosóficas, suas constantes citações ou sua incontrolável intertextualidade, True Detective se oferece para ser analisada (e desfrutada numa segunda rodada) a partir de uma metodologia da atração efetiva: 0 texto busca 0 texto [...] (2014a, p. 34, tradução nossa). ${ }^{11}$

Enfatiza-se, assim, 0 arquipélago textual (ABRIL, 2012) da série, que se caracteriza por uma intensa comunicabilidade com outros textos, configurando-se como um mapa de diálogos e confrontações com seus referentes, em viagens que se dão por um verdadeiro labirinto metaficcional (HERNÁNDEZ; RÍOS, 2014). True Detective convoca diversas referências para compor sua trama: além do livro de Chambers, a literatura de Ambrose Bierce, H.P. Lovecraft, Dashiell Hammett, Thomas Ligotti e Roberto Bolaño; o pensamento de Arthur Schopenhauer e de Friedrich Nietzsche; as séries da HBO como The wire (2002-2008) e Deadwood (2004-2006); 0 cinema de Michael Mann e os personagens clássicos de John Wayne, para ficar em alguns exemplos assumidos por Pizzolatto (JENSEN; PIZZOLATTO, 2014). Diversos outros diálogos textuais são levantados pelos fãs da série, em compilações pela internet, que destacam filmes como $O$ abrigo (Take shelter, Jeff Nichols, 2011) e Pecados antigos, longas sombras (La isla mínima, Alberto Rodríguez, 2014), bem como séries como Twin Peaks (ABC, 1990-1991; Showtime, 2017) e Hannibal (NBC, 2013-2015).

Quando o telespectador busca encontrar sentidos para a referência ao Rei Amarelo, essa pista ilustra o jogo de sedução e trapaça que marca a série. Todos os que foram ler o livro de Chambers

10 Bailemos, descubramos a algún escritor que no conocíamos, leamos por fin a ese otro, sigamos alguna pista falsa, colguemos fichas e imágenes en una pared para intentar visualizar nuestro caso, echemos un paso atrás, hay fotos de autores muertos y vivos, citas inconexas, portadas de libros. [...] Queremos saber más [...]. Saberlo todo. Queremos descubrir los referentes literarios de la narración audiovisual mientras avanza el metraje y los protagonistas descubren al asesino. Doble investigación, ¿doble placer?

11 Por sus múltiples referencias literarias y filosóficas, sus constantes citas o su apabullante intertextualidad, True Detective se ofrece para ser analizada (y disfrutada en segunda vuelta) desde una metodología de la atracción efectiva: el texto busca el texto [...]. 
na esperança de encontrar respostas caíram num embuste. Admitindo que True Detective pautase numa "lógica do equívoco" (RÍOS, 2014b), podemos apostar que a conduta errática no modo de lidar com pistas transcende os personagens e envolve o telespectador. Como analisa Ríos,

[...] duvido muito que o leitor compulsivo de weird fiction em geral e 0 de Robert Chambers em particular tenha encontrado em suas páginas a resolução de algum enigma em relação a True Detective, especialmente no que tange à identidade do monstro ao final do sonho do qual nos falava Rust. Na realidade, quando um espectador de True Detective lê um conto como "0 emblema amarelo" [de 0 Rei de Amarelo], é provável que [...] o leitor imagine uma hipótese segundo a qual Chambers serviu para Pizzolatto intensificar, de maneira elegante, a lógica do equívoco e da pista falsa subjacente em True Detective [...]. Em outras palavras: o Rei Amarelo não é nada. Ao menos nada na mente de Pizzolatto [...]. Mas seguramente é algo, ou mais exatamente, a ausência de algo, o rastro deixado por algo que já não é. No universo de True Detective, o Rei Amarelo é a pista falsa, a condição de possibilidade para a convivência narrativa de um amálgama de histórias que Rust e Marty vão contando a si mesmos ao longo dos anos [...] (2014b, p. 106, grifos nossos, tradução nossa). ${ }^{12}$

0 Rei Amarelo seria, portanto, o símbolo do quão lacunar são as pistas - ou o próprio texto, em sua natureza aberta e de infinita potencialidade.
Em True Detective, essa característica ganha em potência a partir das pistas ignoradas pelos investigadores, de modo que pouco é descoberto, mas muito é sugerido - inclusive pelo telespectador. Nesse sentido, ao analisar a literatura criminal atual, Lyslei Nascimento afirma:

Não há chave para abrir qualquer mistério. 0 texto policial contemporâneo [...] não é um desafio à inteligência pura, premiada com um final em que todos os papéis são descortinados diante de uma plateia expectante, como nas narrativas de Conan Doyle ou Agatha Christie. 0 leitor contemporâneo de narrativas policiais é, como a escrita, também uma instância a ser desconstruída. 0 que resta ao leitor, além do embaralhamento de vozes, é uma desconfortante busca, em que o que se espera dele é que confie, desconfiando, em verdades apenas provisórias. [...] 0 leitor, mesmo ficcionalizado, aparecendo no texto, como um narratário confiável, é desafiado a, paradoxalmente, não confiar na primeira história ou na segunda, como queria Todorov, mas deixar que essa "semiesquizofrenia", a vertigem, também dirija ou direcione seu olhar, sua leitura (NASCIMENTO, 2011, p. 35).

Problematiza-se, assim, a questão mesma do saber, tão essencial à gênese da ficção criminal: 0 que é "descobrir a verdade", "identificar pistas", "recontar o passado", "conhecer a realidade"? Diante da eterna dúvida do detetive - que descobrimos ser apenas mais um personagem às

12 [...] dudo mucho de que el lector compulsivo de weird fiction en general y el de Robert Chambers en particular haya encontrado en sus páginas la resolución de algún enigma en relación con True Detective, especialmente del que tiene que ver con la identidad del monstruo al final del sueño del que nos hablaba Rust. En realidad, cuando un espectador de True Detective lee un relato como 'El signo amarillo' es probable que [...] el lector figure una hipótesis según la cual Chambers ha servido a Pizzolatto para intensificar de manera elegante la lógica de equívoco y la pista falsa que subyace en True Detective [...]. En otras palabras: el Rey Amarillo no es nadie. Al menos nadie en la mente de Pizzolatto. [...] Pero seguramente sea algo, o más exactamente, la ausencia de algo, la huella dejada por algo que ya no está o no es. En el universo de True Detective, el Rey Amarillo es la pista falsa, la condición de posibilidad para la convivencia narrativa de una amalgama de historias que Rust e Marty van contándose a sí mismos a lo largo de los años [...]. 
voltas com o enigma insolúvel de re-construir 0 passado, e não um gênio de mente privilegiada -, nos vemos em um universo em que 0 telespectador se volta, como nunca, ao papel de mais um a tentar resolver o mistério.

Podemos, portanto, ir mais longe em nossas aproximações: ao instituir o leitor/telespectador como detetive, num convite à exploração dos truques e artimanhas para desvendar o mistério, a narrativa criminal pode conter o germe dos leitores analistas e críticos previstos tanto por Eco quanto por Mittell (que, como dissemos, recorrem a analogias com histórias policiais).

No entanto, alerta Figueiredo:

[...] ao atualizar o gênero policial, a ficção contemporânea não está interessada em desviá-lo de seu destino comercial ou em dissolvê-lo em meio à livre pesquisa estética. Está interessada na apropriação de uma estrutura de gênero que, desde 0 século XIX, vem funcionando como um sistema de convenções que circula entre a indústria editorial, 0 texto e 0 leitor. 0 gênero policial, apropriando-se do esquema de investigação de crimes instituído pela modernidade, para transformá-lo numa espécie de modelo gerador de narrativas, caracteriza-se pelo amplo potencial de reprodução a partir de pequenas variações, adaptando-se bem ao princípio da serialidade e à transposição para diferentes mídias. Afina-se assim também com uma sociedade regida pela vertigem da reprodutibilidade incessante, mas que não abre mão do inventário e do controle. A analogia entre 0 detetive $\mathrm{e}$ 0 voyeur, que Hitchcock já explorava no filme Janela Indiscreta (EUA, 1954), pode ser estendi$\mathrm{da}$, hoje, àquele espectador que se diverte com a indiscrição, com a possibilidade de devassar a vida privada, o cotidiano do outro, diante de uma tela de televisão ou de computador - as redes sociais oferecem ao detetive/voyeur um vasto campo de observação (FIGUEIREDO, 2013, p. 13-14).

Se esse leitor/telespectador-detetive emerge no histórico há mais de cem anos, a televisão contemporânea não faz outra coisa que não se apropriar de uma estratégia consagrada e adaptá-la às suas necessidades comerciais e comunicativas. Assim, a constituição do telespectador-detetive pode não ser nada mais que uma sacada, um apelo, uma estratégia comercial. Nesse sentido, seria um fenômeno pouco inovador. Nessa perspectiva, a experiência espectatorial das narrativas complexas seria, a princípio, conservadora, por mais que baseada em narrativas e narradores pouco confiáveis.

No entanto, se ler é um ato violento, que mata sentidos em favor de outros (FELMAN, 1977), no caso de True Detective, podemos pensar sua narrativa como uma sequência sem fim de crimes. Quebrando os dois níveis de histórias propostas por Todorov (2006) no seu clássico estudo sobre as narrativas criminais, temos o crime de Errol, as mentiras dos detetives, a versão do macronarrador e as novas propostas do telespectador: sentidos surgem e morrem para originar novos, numa cadeia sem fim. Mais do que um jogo de ganhar ou perder (dinâmica normalmente associada à narrativa criminal), True Detective propõe uma competição de outra ordem, mais sofisticada. A série não trata de se estar certo ou errado, pois questiona não apenas 
a veracidade do discurso, mas a possibilidade própria de um discurso conter uma verdade.

\section{Considerações finais}

Nesse momento, um ponto de escape se introduz no entendimento do telespectador-detetive como uma figura conservadora. Como bem alerta Ricoeur, em sua crítica à Estética da Recepção e a categorias como "leitor-implícito" (e leitor-modelo, por extensão), a experiência de "leitura" (ou de assistir a uma série televisiva) não se esgota na construção de uma proposta comunicativa (que tais categorias materializam). Afinal, diz ele, "[...] a fenomenologia do ato de leitura, para dar toda sua amplitude ao tema da interação, precisa de um leitor de carne e osso, que, realizando o papel do leitor preestruturado no e pelo texto, o transforma" (2010, p. 292, grifos do original). Assim, a experiência da leitura pode ser vista como um combate entre o texto, a narrativa, e seu interlocutor, que detém a paradoxal condição de "liberdade coagida", uma vez que sua ação precisa dos constrangimentos textuais. Há, com isso, um entendimento acerca da experiência da leitura que reconhece que

[q]uando o leitor submete suas expectativas às que 0 texto desenvolve, ele irrealiza a si mesmo na mesma proporção da irrealidade do mundo fictício para o qual emigra [...]. Em contrapartida, quando o leitor incorpora - conscientemente ou inconscientemente, pouco importa - os ensinamentos de suas leituras à sua visão de mundo, para aumentar sua legibilidade prévia, a leitura é para ele algo diferente de um lugar onde ele para; ela é um meio que ela atravessa. (RICOEUR, 2010, p. 308, grifos do original).
Um narrador não confiável seria então uma estratégia de abertura, de ampliação da demanda de ação do leitor/espectador. Nada garante, no entanto, que o espectador de carne-e-osso, mesmo aderindo ao jogo narrativo, se inquiete, reassista, perfure ou se inquira sobre possibilidades e sentidos, nem que seu agir se esgote na montagem de quebra-cabeças metanarrativo ou que se estenda ao seu modo de ver o mundo. Nada garante sua errância ou mesmo a qualidade do seu gesto crítico. Mas é possível identificar narrativas cuja demanda contenha uma potência de provocação, de perigo, de estranhamento. True Detective parece ser uma delas, ao por em questão a própria possibilidade da verdade.

A imagem do telespectador-detetive apresenta-se, portanto, como uma chave de leitura interessante, mas incompleta, talvez insuficiente. Afinal, a experiência de mundos ficcionais que ela descreve parece ser bem antiga, sendo constantemente retomada, atualizada, seja para fins efêmeros ou duradouros. É importante lembrar, aliás, que temos, na tradição das narrativas criminais, diferentes modos de ser detetive, dos apáticos e burocráticos aos mais cartesianamente racionais, infalíveis e certeiros, aos passionais, violentos, loucos, viciados, inseguros e/ou questionadores. E não é 0 fato de reassistirmos, de perfurarmos, que vai garantir uma maior ou menor identificação como esta ou aquela imagem de detetive. Em outras palavras, que fazemos, nós, diante de séries como True Detective? Aceitamos suas 
provocações, procuramos verdades, referência, segurança nas pistas disponíveis, assumimos a incerteza, seguimos em frente (talvez na busca de mais uma série)?

\section{Referências}

ABRIL, Gonzalo. Tres dimensiones del texto y de la cultura visual. Revista Científica de Información y Comunicación. Espanha: 2012. Pags: 15-35.

BAHIANA, Ana Maria. O final de True Detective: mil e uma noites no sul da Louisiana. Uol. 10 mar. 2014. Disponível em http://anamariabahiana.blogosfera.uol. com.br/2014/03/10/o-final-de-true-detective-mil-e-umanoites-no-sul-da-louisianna/. Acesso em: 08 fev. 2017.

B00TH, Wayne C. A retórica da ficção. Trad. Maria Teresa Guerreiro. Lisboa: Arcádia, 1980.

BURIAN, Fran; CORRETGER, Glòria. La imagenlaberinto en la ficción televisiva norteamericana contemporánea. Series de tiempo y mundos virtuales. In: PÉREZ-GÓMEZ, Miguel A (org.). Previously 0n: Estudios interdisciplinarios sobre la ficción televisiva en la Tercera Edad de Oro de la Televisión. Sevilha: Biblioteca de la Facultad de Comunicación de la Universidad de Sevilla, 2011.

COMPAGNON, A. O mundo. In: 0 demônio da teoria: literatura e senso comum. Trad. Cleonice Paes Barreto Mourão. Belo Horizonte: UFMG, 1999.

EC0, Umberto. A inovação no seriado. In: Sobre espelhos e outros ensaios. Rio de Janeiro: Nova Fronteira, 1989. Interpretação e superinterpretação. Trad. MF. Rev. trad. Monica Stahel. 2. ed. São Paulo: Martins Fontes, 2005.

FELMAN, Shoshana. Turning the screw of interpretation. Yale French Studies. New Haven: Yale University, 1977.
FIGUEIRED0, Vera Lúcia Follain de . O Assassino e o Leitor. Matraga (Rio de Janeiro), RIO DE JANEIRO, v. 3, n.4/5, p. 20-26, 1988.

O gênero policial como máquina de narrar.

Dispositiva - Revista do Programa de Pós-Graduação em Comunicação Social da Faculdade de Comunicação e Artes da PUC Minas, v. 2, p. 2, 2013.

HERNÁNDEZ, Rubén; RÍOS, Iván de los. Prólogo del editor. In: HERNÁNDEZ, Rubén. RÍOS, Iván de los (org.). True Detective: Antología de lecturas no obligatorias. Madrid: Errata Naturae, 2014.

JEHA, Julio. Ética e estética do crime: ficção de detetive, hard-boiled e noir. In: 12. Congresso Internacional da Abralic, 2011, Curitiba. Centro Ética, Estética. Curitiba: Abralic, 2011.

JENSEN, Jeff; PIZZOLATTO, Nic. True Detective y las historias que nos contamos. In: HERNÁNDEZ, Rubén. RÍOS, Iván de los (org.). True Detective: Antología de lecturas no obligatorias. Madrid: Errata Naturae, 2014.

JOST, François. Do que as séries americanas são sintoma? Porto Alegre: Sulina, 2012.

MALMGREN, Carl D. Anatomy of murder: Mystery, Detective and Crime Fiction. Bowling Green: Popular Press, 2001.

MITTELL, Jason. Forensic Fandom and The Drillable Text. Spreadable Media, 2009. Disponível em: http:// spreadablemedia.org/essays/mittell/\#.VYhx5flViko. Acesso em: 28 dez. 2016.

. Notes on Rewatching. Just TV. 27 jan.

2011. Disponível em: https://justtv.wordpress. com/2011/01/27/notes-on-rewatching/. Acesso em: 28 dez. 2016.

Complexidade narrativa na televisão americana contemporânea. Revista Matrizes. Ano 5 - no 2 jan./jun. São Paulo - Brasil - p. 29-52, 2012.

MOST, Glenn W. The Hippocratic Smile: John le Carré and the traditions of the detective novel. In: MOST, 
Glenn W.; STOWE William W. (org.). The Poetics of Murder: Detective Fiction and Literary Theory. Nova York: Harcourt Brace Jovanovich, 1983.

NASCIMENTO, Lyslei. Vertigem e desconstrução: a invenção do romance policial contemporâneo. Estado de Minas, v. 1, p. 33-35, 2011.

PELEGRINI, Christian Hugo. A poética do cômico em Arrested Development e a reassistibilidade. Palabra Clave, v. 15, p. 621-648, 2012.

RICOEUR, Paul. Tempo e narrativa, vol. 3 - 0 tempo narrado. São Paulo: WMF Martins Fontes, 2010.

RÍOS, Ivan de los. Arcano es todo menos nuestro dolor: Ensayo sobre True Detective. In: HERNÁNDEZ, Rubén. RíOS, Iván de los (org.). True Detective: Antología de lecturas no obligatorias. Madrid: Errata Naturae, 2014a. . Nic Pizzolatto y El Rey Ausente: Presentación. In: HERNÁNDEZ, Rubén. RÍOS, Iván de los (org.). True Detective: Antología de lecturas no obligatorias. Madrid: Errata Naturae, 2014b.

SEPINWALL, Alan. 'True Detective' creator on his gripping new HBO series. Uproxx. 07 jan. 2014. Disponível em: http://uproxx.com/sepinwall/ true-detective-creator-nic-pizzolatto-on-matthewmcconaughey-woody-harrelson-his-gripping-new-hboseries/. Acesso em: 08 fev. 2017.

SILVA, M. V. B.. Cultura das séries: forma, contexto e consumo de ficção seriada na contemporaneidade. Galáxia (São Paulo. Online), v. 14, p. 241-252, 2014.

TODOROV, Tzvetan. As estruturas narrativas. São Paulo: Perspectiva, 2006.

TOLEDO, G. M... Perfurabilidade em seriados: espectadores como investigadores em Game of Thrones. In: XXV Encontro Anual da Compós, 2016, Goiânia, GO. Anais -> 2016 - XXV COMPÓS: GOIÂNIA/ G0, 2016. v. 1. 


\section{The TV viewer as detective:} approaches to the contemporary television experience from HBO's True Detective

\section{Abstract}

From the study of the first season of True Detective, this paper analyses the image of the TV viewer as a detective in search of meanings and relations present in the stories watched. The HBO show, which is guided by unreliable narrators, summons a viewer interested in "drilling" and rewatch the story, to use the terms coined by Jason Mittell (2009). Throughout the paper, we reflect on the extent to which this viewer posture, which parallels the suspicious reader predicted by Paul Ricoeur (2010), constitutes a critical movement beyond the series or is exhausted in a metanarrative pleasure. In the case of True Detective, the very possibility of a speech to contain a truth is put at stake, in what can be its main contribution in regard to the performance of the television viewer-detective.

\section{Keywords}

Narrative. Series. Viewer. Television. Fiction.

\section{El telespectador como detective:} aproximaciones a la experiéncia televisiva contemporánea desde True Detectve, de HBO

\section{Resumen}

A partir de la analisis de la primera temporada de True Detective, el artículo explora la imagen del espectador contemporáneo como un detective en busca de sentidos y relaciones para las narrativas con las que se involucra. El programa de HBO, cuya trama es guiada por narradores no confiables, convoca a un espectador interesado en "perforar" y "reasistir" su narrativa, conforme terminología acuñada por Jason Mittell (2009). A lo largo del trabajo, reflexionamos en qué medida esta postura telespectatorial, que encuentra paralelo con el lector desconfiado destacado por Paul Ricoeur (2010), constituye un movimiento crítico más allá de la serie o se agota en un placer metanarrativo. En el caso de True Detective, la propia posibilidad de que un discurso contenga una verdad es colocada en jaque, en lo que puede ser su principal contribución en lo que se refiere a la actuación del espectador-detective.

\section{Palabras clave}

Narrativa. Serie. Telespectador. Televisión. Ficción. 


\section{Expediente}

A revista E-Compós é a publicação científica em formato eletrônico da Associação Nacional dos Programas de Pós-Graduação em Comunicação (Compós). Lançada em 2004, tem como principal finalidade difundir a produção acadêmica de pesquisadores da área de Comunicação, inseridos em instituições do Brasil e do exterior.

\section{E-COMPÓS I www.e-compos.org.br I E-ISSN 1808-2599}

Revista da Associação Nacional dos Programas de Pós-Graduação em Comunicação. Brasília, v.20, n.3, set./dez. 2017. A identificação das edições, a partir de 2008 , passa a ser volume anual com três números. Indexada por Latindex I www.latindex.unam.mx

\section{CONSELHO EDITORIAL}

Ada Cristina Machado Silveira, Universidade Federal de Santa Maria, Brasil Alda Cristina Silva da Costa, Universidade Federal do Pará, Brasil Alfredo Luiz Paes de Oliveira Suppia, Universidade Estadual de Campinas, Brasil Ana Regina Barros Rego Leal, Universidade Federal do Piauí, Brasil Ana Carolina Rocha Pessôa Temer, Universidade Federal de Goiás, Brasil André Luiz Martins Lemos, Universidade Federal da Bahia, Brasil Angela Cristina Salgueiro Marques, Universidade Federal de Minas Gerais, Brasil Ângela Freire Prysthon, Universidade Federal de Pernambuco, Brasil Antonio Carlos Hohlfeldt, Pontifícia Universidade Católica do Rio Grande do Sul, Brasil Arthur Ituassu, Pontifícia Universidade Católica do Rio de Janeiro, Brasil

Bruno Campanella, Universidade Federal Fluminense, Brasil

Cláudio Novaes Pinto Coelho, Faculdade Cásper Líbero, Brasil Cárlida Emerim, Universidade Federal de Santa Catarina, Brasil Carlos Eduardo Franciscato, Universidade Federal de Sergipe, Brasil Danilo Rothberg, Universidade Estadual Paulista, Brasil Denise Tavares da Silva, Universidade Federal Fluminense, Brasil Diógenes Lycarião, Universidade Federal do Ceará, Brasil Eduardo Vicente, Universidade de São Paulo, Brasil Eliza Bachega Casadei, Escola Superior de Propaganda e Marketing - SP, Brasil Eneus Trindade, Universidade de São Paulo, Brasil

Erick Felinto de Oliveira, Universidade do Estado do Rio de Janeiro, Brasil Erly Vieira Júnior, Universidade Federal do Espírito Santo, Brasil Francisco de Assis, FIAM-FAAM Centro Universitário, Brasi

Francisco Elinaldo Teixeira, Universidade Estadual de Campinas, Brasil Francisco Gilson R. Pôrto Jr., Universidade Federal do Tocantins, Brasil Frederico de Mello Brandão Tavares, Universidade Federal de Ouro Preto, Brasil Gabriela Reinaldo, Universidade Federal do Ceará, Brasil Gilson Vieira Monteiro, Universidade Federal do Amazonas, Brasil Gustavo Daudt Fischer, Universidade do Vale do Rio dos Sinos, Brasil Itania Maria Mota Gomes, Universidade Federal da Bahia, Brasil Jiani Adriana Bonin, Universidade do Vale do Rio dos Sinos, Brasil José Afonso da Silva Junior, Universidade Federal de Pernambuco, Brasil José Luiz Aidar Prado, Pontifícia Universidade Católica de São Paulo, Brasi Josette Maria Monzani, Universidade Federal de São Carlos, Brasi Juçara Gorski Brittes, Universidade Federal de Ouro Preto, Brasil
Juliana Freire Gutmann, Universidade Federal da Bahia, Brasil Laura Loguercio Cánepa, Universidade Anhembi Morumbi, Brasil Leonel Azevedo de Aguiar, Pontifícia Universidade Católica do Rio de Janeiro, Brasil Letícia Cantarela Matheus, Universidade do Estado do Rio de Janeiro, Brasil Luciana Coutinho Souza, Universidade de Sorocaba, Brasil Maria Ataide Malcher, Universidade Federal do Pará, Brasil Maria Elisabete Antonioli, Escola Superior de Propaganda e Marketing - SP, Brasil Maria das Graças Pinto Coelho, Universidade Federal do Rio Grande do Norte, Brasil Marialva Carlos Barbosa, Universidade Federal do Rio de Janeiro, Brasil Marcel Vieira Barreto Silva, Universidade Federal da Paraíba, Brasil Marcia Tondato, Escola Superior de Propaganda e Marketing, Brasil Marli Santos, Universidade Metodista de São Paulo, Brasil

Márcio Souza Gonçalves, Universidade do Estado do Rio de Janeiro, Brasil Mauricio Mario Monteiro, Universidade Anhembi Morumbi, Brasil Mayka Castellano, Universidade Federal Fluminense, Brasil

Mozahir Salomão Bruck, Pontifícia Universidade Católica de Minas Gerais, Brasil Nisia Martins Rosario, Universidade Federal do Rio Grande do Sul, Brasil Paolo Demuru, Universidade Paulista, Brasil

Paula Melani Rocha, Universidade Estadual de Ponta Grossa, Brasil Potiguara Mendes Silveira Jr, Universidade Federal de Juiz de Fora, Brasil Priscila Ferreira Perazzo, Universidade Municipal de São Caetano do Sul, Brasil Rafael Cardoso Sampaio, Universidade Federal do Paraná, Brasil Rafael Tassi Teixeira, Universidade Tuiuti do Paraná, Brasil Regiane Lucas Garcês, Universidade Federal de Minas Gerais, Brasil Regiane Regina Ribeiro, Universidade Federal do Paraná, Brasil Renata Pitombo Cidreira, Universidade Federal do Recôncavo da Bahia, Brasil Renato Essenfelder, Escola Superior de Propaganda e Marketing, Brasil Roberto Elísio dos Santos, Universidade Municipal de São Caetano do Sul, Brasil Rodolfo Rorato Londero, Universidade Estadual de Londrina, Brasil Roseli Figaro, Universidade de São Paulo, Brasil

Simone Maria Andrade Pereira de Sá, Universidade Federal Fluminense, Brasil Sofia Cavalcanti Zanforlin, Universidade Católica de Brasília, Brasil Sônia Caldas Pessoa, Universidade Federal de Minas Gerais, Brasil Tatiana Oliveira Siciliano, Pontifícia Universidade Católica do Rio de Janeiro, Brasil Thaïs de Mendonça Jorge, Universidade de Brasília, Brasil

Valquiria Michela John, Universidade Federal do Paraná, Brasil

\section{CONSELHO CIENTÍFICO}

Cristiane Freitas Gutfreind, Pontifícia Universidade Católica do Rio Grande do Sul, Brasil | Eduardo Antônio de Jesus, Universidade Federal de Minhas Gerais, Brasil I Eduardo Morettin, Universidade de São Paulo, Brasil I Irene de Araújo Machado, Universidade de São Paulo, Brasil I Miriam de Souza Rossini, Universidade Federal do Rio Grande do Sul, Brasil

\section{COMISSÃO EDITORIAL}

Eduardo Antonio de Jesus, Universidade Federal de Minas Gerais, Brasil I Igor Pinto Sacramento, Universidade Federal do Rio de Janeiro, Brasil I Kelly Cristina de Souza Prudencio, Universidade Federal do Paraná, Brasil I Osmar Gonçalves dos Reis Filho, Universidade Federal do Ceará, Brasil I Rafael Grohmann, FIAMFAAM - Centro Universitário, Brasil (editor associado)

\section{CONSULTORES AD HOC}

Afonso de Albuquerque, Universidade Federal Fluminense, Brasil I Francisco Rüdiger, Pontifícia Universidade Católica do Rio Grande do Sul, Brasil I Gislene da Silva, Universidade Federal de Santa Cataria, Brasil I Luiz Cláudio Martino Universidade de Brasília, Brasil I Magali Nascimento Cunha, Universidade Metodista de São Paulo, Brasil I Márcia Franz Amaral, Universidade Federal de Santa Maria, Brasil I Tania Marcia Cezar Hoff, Escola Superior de Propaganda e Marketing, Brasil I Raquel Paiva, Universidade Federal do Rio de Janeiro, Brasil

\section{EQUIPE TÉCNICA}

ASSISTENTE EDITORIAL Márcio Zanetti Negrini I REVISÃO DE TEXTOS Melina Santos I EDITORAÇÃO ELETRÔNICA Roka Estúdio
COMPÓS I www.compos.org.br

Associação Nacional dos Programas de Pós-Graduação em Comunicação

Presidente

Marco Roxo

Programa de Pós-Graduação em Comunicação - UFF marcos-roxo@uol.com.br

Vice-Presidente

Isaltina Gomes

Programa de Pós-Graduação em Comunicação - UFPE

isaltina@gmail.com

Secretária-Geral

Gisela Castro

Programa de Pós-Graduação em Comunicação

e Práticas de Consumo - ESPM

castro.gisela@gmail.com

CONTATO I revistaecompos@gmail.com 